\author{
Military Technical College \\ Kobry El-Kobbah, \\ Cairo, Egypt.
}

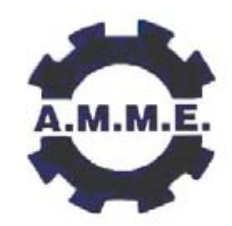

\author{
$13^{\text {th }}$ International Conference \\ on Applied Mechanics and \\ Mechanical Engineering.
}

\title{
ASSESSING THERMAL VARIATION IN BENCH AND CAROUSEL- TYPE PRODUCTION TOOLS
}

\author{
ABDUL-RANI* A.M., AHMAD F** and MURAD*** M. N.
}

\begin{abstract}
Uniform mould temperature is very much desired in foam production tools. Mould temperature variation can result in low part quality. It is suspected that uniform mould temperature is not achieved during foam moulding process. A series of experiments was conducted to assess production tools' mould surface temperature. The work was performed to quantify any temperature variations in existing production tools. It was also intended as a preliminary inspection of any effects on flexible PU foam part quality resulting from tool temperature variations. Experiments were conducted on bench and carousel-type moulds at an industrial plant using non-contact and contact technique to measure and quantify the mould surface temperature. A grid of locations and features on the mould surface are identified and temperature recordings were conducted a number of times for each spot. Distance between mould surface and heating channels for each spot are also noted. It was found that there exists a mould surface temperature variation between $4^{0} \mathrm{C}$ to $8^{\circ} \mathrm{C}$ on some parts of the mould surface. The locality where the mould surface was lower coincided with a negative effect on the final part such as scaling and shrinks mark. It was established through experimental results that the mould surface temperature was affected by the distance from the heating channel to the mould surface. Consequently a uniform distance between heating channel and mould surface was proposed to be incorporated in the design of future production tools to attain a uniform mould surface temperature.
\end{abstract}

\section{KEY WORDS}

Mould Temperature, Polyurethane Foam, Heating Channels

Senior Lecturer, Dept. of Mech. Eng., Universiti Teknologi Petronas, Malaysia.

** Associate Professor, Dept. of Mech. Eng., Universiti Teknologi Petronas, Malaysia.

${ }^{* * *}$ Lecturer, School of Manufacturing Engineering, Universiti Malaysia Perlis, Malaysia. 


\section{INTRODUCTION}

Polyurethane has been the fastest growing segment of the polymer industry since it was discovered by Dr Otto Bayer in the 1940's. Consumption of polyurethanes has grown from 4,000 tonnes in 1956 to over 250,000 tonnes in 1967 [1]. Recent figures show that over 900,000 tonnes are consumed each year by global automotive industries alone [2]. Typical scrap rates of between $2-4 \%$ translate into millions of pounds wasted since the materials cost alone is close to $50 \%$ of the moulded component [3]. Flexible polyurethane foam captures the major foam market for upholstery, mattresses, automotive seats and interiors, carpet backing, packaging and padding [4]. Flexible polyurethane foam moulded products are manufactured by mixing polyol and isocyanate in a preheated tool. The heat from the tool promotes urethane polymerisation and foaming which expands to fill the mould cavity. The polymerisation reaction produces solid polyurethane and it is by forming bubbles in the polymerising mixture that a foam is made. The name urethane is derived from Latin, urina for urine, and French ethan for ethanol [5].

In foam production plants the polyurethane foams are cured in heated moulds during the production cycle. Heating of moulds can be performed either by heated fluids (e.g. $\mathrm{H}_{2} \mathrm{O}$ or oil) in channels, convection hot-air oven, radiant heating or microwave radiation. Small plants (up to 20 units approximately) usually condition the moulds with independent heating units while big plants producing a high number of moulded flexible foam parts such as cushions for the car industry normally implement a hot-air oven for mould heating [6]. Uniform mould temperature is very much desired in foam production tools [7]. It is suspected that uniform mould temperature is not achieved during foam moulding process resulting in low part quality.

\section{BENCH AND CAROUSEL-TYPE MOULDS}

Depending on the size and number of the foam parts to be produced, the mould can either be a bench-type, floor-type or a series of moulds mounted on a carousel. Small sized parts are usually produced in bench-type moulds (Fig. 1), while larger parts are produced in floor-type moulds.

Parts required in high volumes are produced in moulds placed on a carousel moving on an oval track. A cam-action top-lid rail achieves opening and closing of moulds, for pouring polyurethanes into the open moulds during mould filling and removal of foam parts. Dispensing of polyurethane into moulds is mainly performed manually but improvements in automation have allowed automatic dispensing or injection of polyurethanes using industrial robots (Fig. 2).

\section{RESEARCH AIM AND OBJECTIVE}

This research work set about in investigating and understanding the existing temperature variations across small and large moulds in production plants. A contact and non-contact approach was adopted to measure and quantify mould temperature variations and investigate factors resulting from uneven mould temperature variations. 
The aim of this research is to investigate, analyse and quantify any mould temperature variations in moulds used at production plants and investigate factors resulting from uneven mould temperature variations. The work was performed to quantify any temperature variations in existing production tools. It was also intended as a preliminary inspection of any effects on flexible PU foam part quality resulting from tool temperature variations.

\section{MOULD TEMPERATURE DISTRIBUTION ON BENCH-TYPE MOULDS}

The measurement of mould surface temperature was executed using the non-contact thermal probe Raytek MX2 shown in Fig. 3 on a range of cold-cure flexible polyurethane moulds at Collins \& Aikman. This thermal probe has a temperature range from $-30^{\circ} \mathrm{C}$ to $900^{\circ} \mathrm{C}$, and good optics ratio for measuring from a distance of up to more than one meter. The probe utilises a coaxial laser sighting system to provide precise infrared beam tracking, resulting in more accurate measurement for critical readings at very specific areas on the mould surface. It is very light and portable making it suitable for the purpose of initial testing.

The experimental work was conducted during normal production to assess the existing temperature distributions across two foam tools with conventional heating channels. The first foam tool, an actual production tool (Fig. 4a), was fabricated from cast aluminium and the second tool, a test tool (Fig. 4b), was a steel laminated tool incorporating conformal heating channels designed and manufactured at Loughborough University. Both tools were heated by hot-water supplied from a heater set at $53^{\circ} \mathrm{C}$. A grid of 15 locations was produced (Fig. 5) and temperature recordings were conducted 3 times for each spot.

\section{MOULD TEMPERATURE DISTRIBUTION ON CAROUSEL-TYPE MOULDS}

This work was performed to assess the thermal conditions on the carousel-type moulds in a production plant (Fig. 6a). The identified carousel was the C21 station at Collins \& Aikman Limited that was running the cold-cure flexible polyurethane process. There were 20 carriages with moulds and one carriage with a compressor circulating around the carousel in the layout shown in Fig. 6b. The main materials used for mixing were VENOM polyether polyol (black compound) and modified diphenylmethane diisocyanate (modified-MDI) commercial name LUCI. Both materials were supplied by Huntsman Polyurethanes and were pre-mixed with various unspecified additives. The cycle time for the whole carriage system was 10 minutes. Individual heaters were assigned to each mould carriage which allowed for pre-setting of the mould temperature. Depending on the specific process requirement of each mould, the temperatures were pre-set ranging between $50^{\circ} \mathrm{C}$ to $60^{\circ} \mathrm{C}$.

The tools identified for the thermal assessment exercise were Tool 2, Tool 7 and Tool 19 producing the same product. This was the engine-side dash cover for the left-hand drive Land-Rover Freelander (Fig. 7). 


\section{FEATURE IDENTIFICATION}

Since Tool 2, Tool 7 and Tool 19 were very large moulds (Fig. 8) recordings of the mould surface temperature were taken according to identified features on the mould surface instead of adopting the previous method of matrix representation. A total of eight distinctive features were identified and assigned in alphabetical order from $\mathrm{A}$ to $\mathrm{H}$ as shown in Fig. 9 to Fig. 16. Some features were further away from the heating channels than others. The required mould running temperature for these three tools was $54^{\circ} \mathrm{C}$.

\section{RESULTS ON BENCH-TYPE MOULDS}

The mould surface temperature for both Tool 1 (cast Aluminium tool) and Tool 2 (laminated tool) were measured and recorded using the non-contact infrared thermometer immediately after demoulding. This exercise was conducted three times at each location and results were assigned as $1^{\text {st }}, 2^{\text {nd }}$ and $3^{\text {rd }}$ reading. The results are tabulated in Table 1 for Tool 1 and Table 2 for Tool 2. Occurrences of highest and lowest temperatures for both tools for each reading are indicated with red and blue circles respectively. The range or the maximum variation between the highest temperature and the lowest temperature for each reading is noted at the bottom of each table. The ranges for the three thermal recordings of both tools are tabulated and the average from the three readings is shown in Table 3.

\section{RESULTS ON CAROUSEL-TYPE MOULDS}

The measurements were conducted during normal plant production operation through two shifts. The data obtained from the experiment clearly indicated the existence of mould surface temperature variations between tools, within each tool and from cycle to cycle as shown in Table 4.

Table 4c shows the Average Temperatures for Tool 19 with the lowest average temperature at $48.1^{\circ} \mathrm{C}$. The lowest Average Temperature for Tool 2 and Tool 7 was $51.7^{\circ} \mathrm{C}$ and $50.5^{\circ} \mathrm{C}$ respectively. A uniform temperature close to the target of $54^{\circ} \mathrm{C}$ was not attained. The quality of parts especially from Tool 19 which was well below the target was affected compared to parts from Tool 2 as shown in Fig. 17 to Fig. 19 below.

\section{DISCUSSIONS}

The temperature variation range between the highest temperature and lowest temperature for each reading was calculated. It was found that Aluminium cast tool have a lower range as compared to Laminate tool. The temperature variation range of the Aluminium cast tool was much lower (averaging at $4.0^{\circ} \mathrm{C}$ ) as compared to the Laminate tool, which had an average temperature variation range of $6.6^{\circ} \mathrm{C}$. This was probably due to cast Aluminium being a more conductive material as compared with laminated steel. Additionally conductive heat transfer across laminates might have been slightly lower than that within laminates. 
It was noted that the lowest mould surface temperature was consistently at the same matrix location D3 on the laminated tool. Similarly for Aluminium cast tool the lowest mould surface temperature was in the same region of D2/D3. The highest temperature point for the Aluminium cast tool was at $\mathrm{B} 1$ for $1^{\text {st }}$ and $2^{\text {nd }}$ reading but at $\mathrm{C} 3$ for the $3^{\text {rd }}$ reading probably due to error in recording. The laminated tool which had a slightly different heating channel design recorded the highest temperature for $1^{\text {st }}$ reading at E2 and then at $A 2$ for $2^{\text {nd }}$ and $3^{\text {rd }}$ reading which is one of the closest point between the heating channel and mould surface.

Temperature data recorded from the laminate tool was plotted to show the relationship between mould surface temperature and distance from heating channel to tool surface. Additionally, a steady state and transient heat transfer FEA model was created and run to predict the thermal conditions in laminate tools with heating fluids in conformal channels at $60^{\circ} \mathrm{C}$. Fig. 20 shows a plot of tool surface temperature against the distance of the surface from the closest heating channel from an FEA model and from physical measurements taken during production. The plot shows a similar trend between the experimental results and the FEA model. This confirms that its distance from heating channel affects mould surface temperature. The actual results in Fig. 20 do show some variability as might be expected from further issues such as exotherm from the curing PU that was not included in the FEA model. The slopes of the graphs are similar indicating that FEA can provide a reasonable prediction of surface tool temperatures.

\section{CONCLUSION}

The analysis established that a temperature variation across the mould surface existed. Mould surface temperature was also shown to vary from cycle to cycle. It was established through experimental results, and supported by the FEA work, that the distance from the heating channel to the mould surface affects the mould surface temperature. Initial investigations had indicated that the temperature variation may affect foam quality and in some cases result in scrap. Although it was difficult to assess and evaluate the quality of foam samples surface texture the qualitative analysis does indicate an effect on surface texture due to mould temperature. Industrial tools were found to be between $4^{0} \mathrm{C}$ to $8^{0} \mathrm{C}$ and it was shown that tools that were cooler appeared to produce inferior foam part surfaces. It was also shown that mould temperature was affected by the distance from the heating channel in line with results from finite element analysis. Preliminary experimental work and inspection conducted on existing production tools at industrial sites indicated that temperature variation affect the quality of the foam surface texture. The general overall appearance of the foam surface was studied and defects noted.

\section{REFERENCES}

[1] Oertel, G. (Editor), Polyurethane Handbook, Carl Hanser Verlag, Munich, ISBN 1-56990-157-0, (1994).

[2] Randall, D. and Lee, S. (Editors), "The Polyurethanes Book", John Wiley \& Sons, ISBN 0-470-85041-8, (2002).

[3] Hopkinson, N. and Dickens, P., "Use of Conformal Heating and Cooling Channels to Enhance Polyurethane Foam Moulding Applications", Grant Proposal, Loughborough University, Loughborough, (2000). 
[4] Morton-Jones, D. and Ellis, J., "Polymer Products: Design, Materials and Processing", Chapman and Hall, London, ISBN 0-412-27130-3, (1986).

[5] Uhlig, K., "Discovering Polyurethanes", Carl Hanser Verlag, Munich, , ISBN 3446-21022-9, (1999).

[6] Buist, J. M. (Editor), "Developments in Polyurethane-1", Applied Science Publishers, London, ISBN 0-85334-756-5 (1978).

[7] Abdul-Rani, A.M., Hopkinson, N., Dickens, P., "Effect of Mould Temperature on High-resilience (HR) Cold-cure Flexible Polyurethane Foam Surface Texture," Journal of Cellular Plastics; v41 n2, March, ISSN 0021-955X, SAGE Publications, pp.134-151, (2005).

\section{FIGURES AND TABLES}

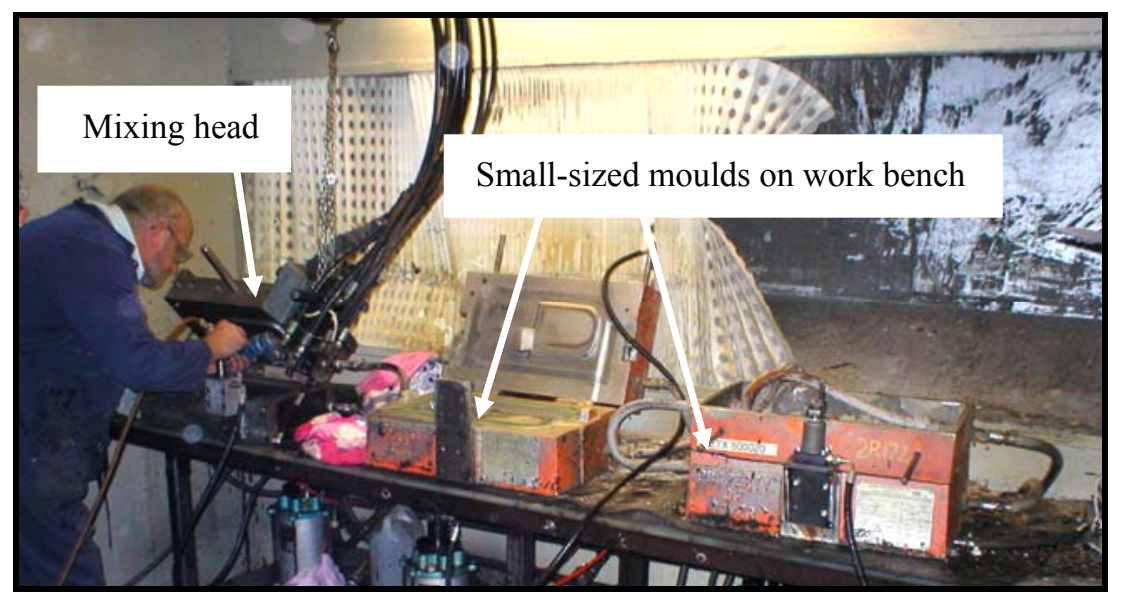

Fig. 1. Bench-type moulds for manufacturing small-sized foam parts.

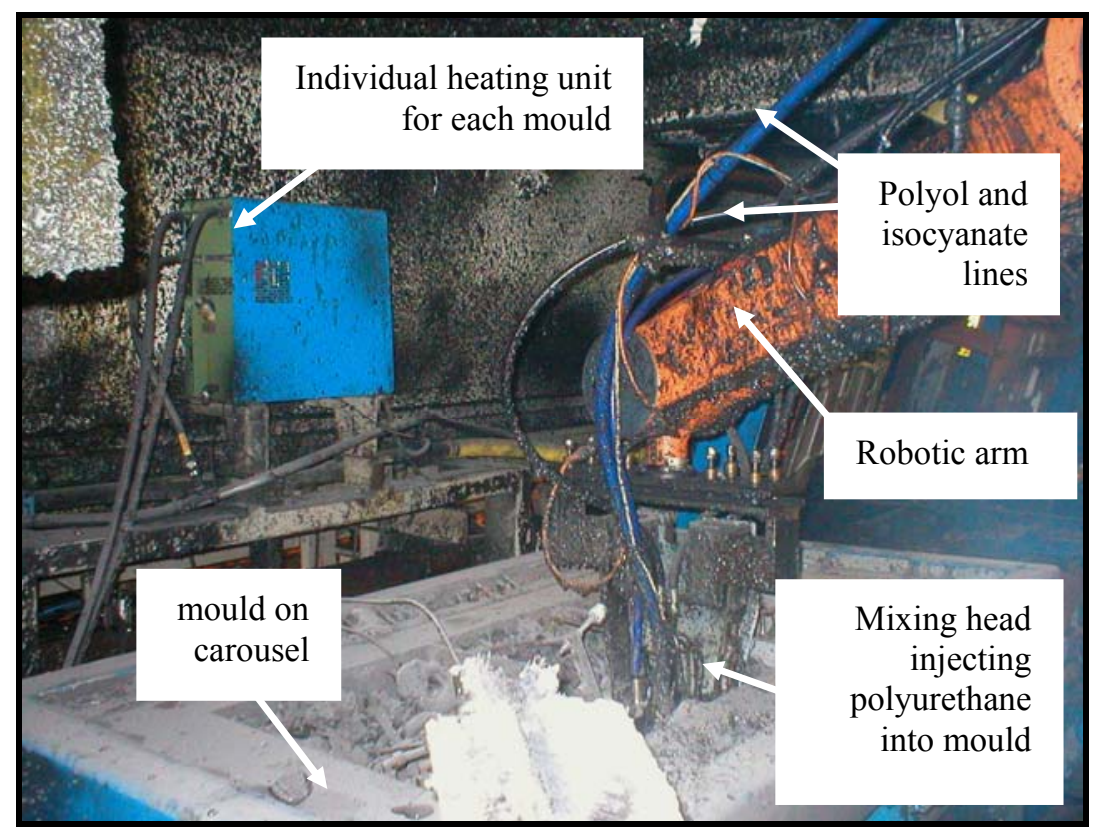

Fig. 2. Robotic arm and heating unit used in foam moulding tool moving on a carousel. 


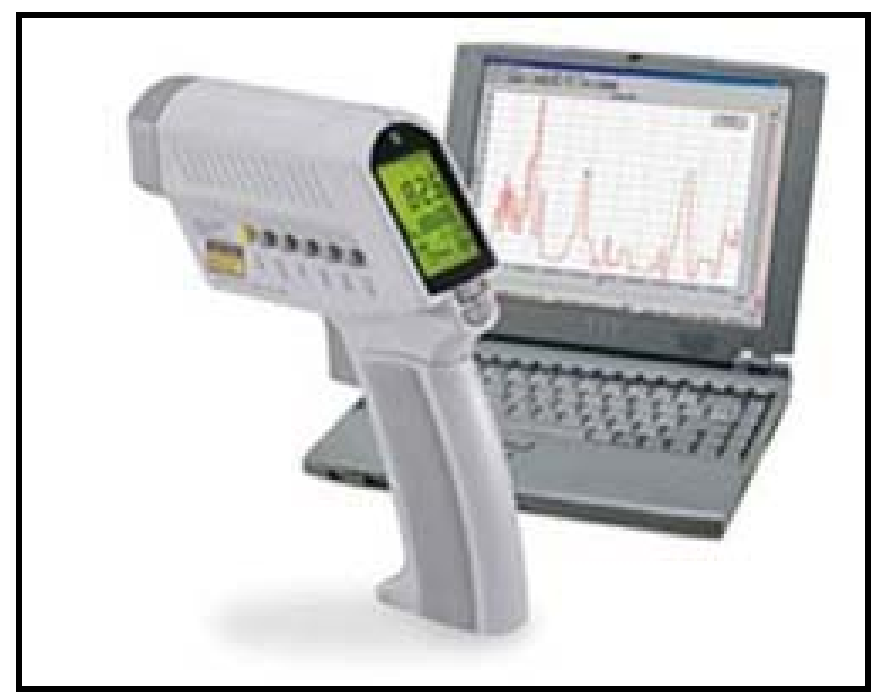

Fig. 3. Raytek non-contact infrared thermometer.

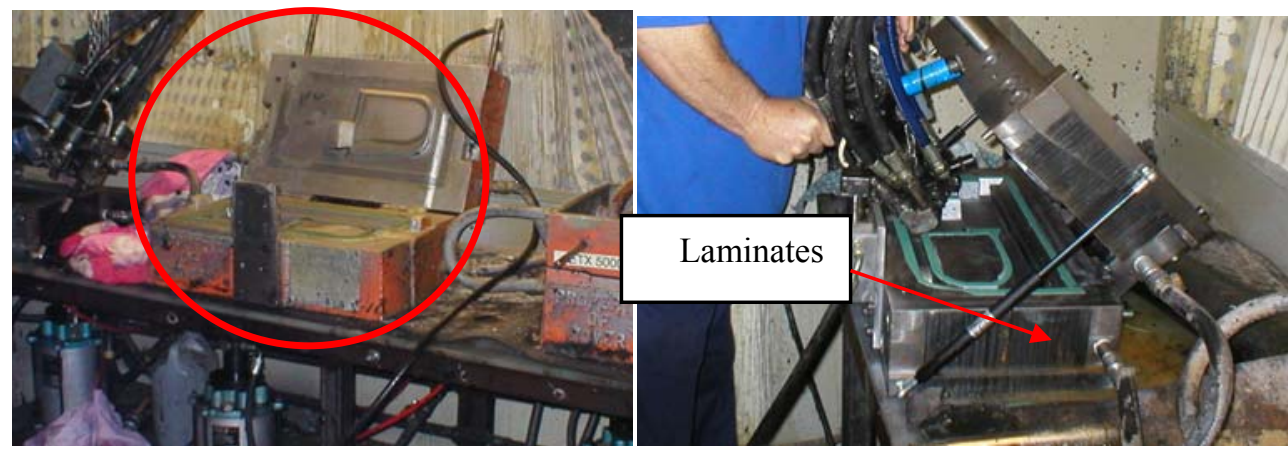

Fig. 4a. Cast Aluminium tool located at centre (circled).
Fig. 4b: Tool 2 Fabricated from steel laminates.

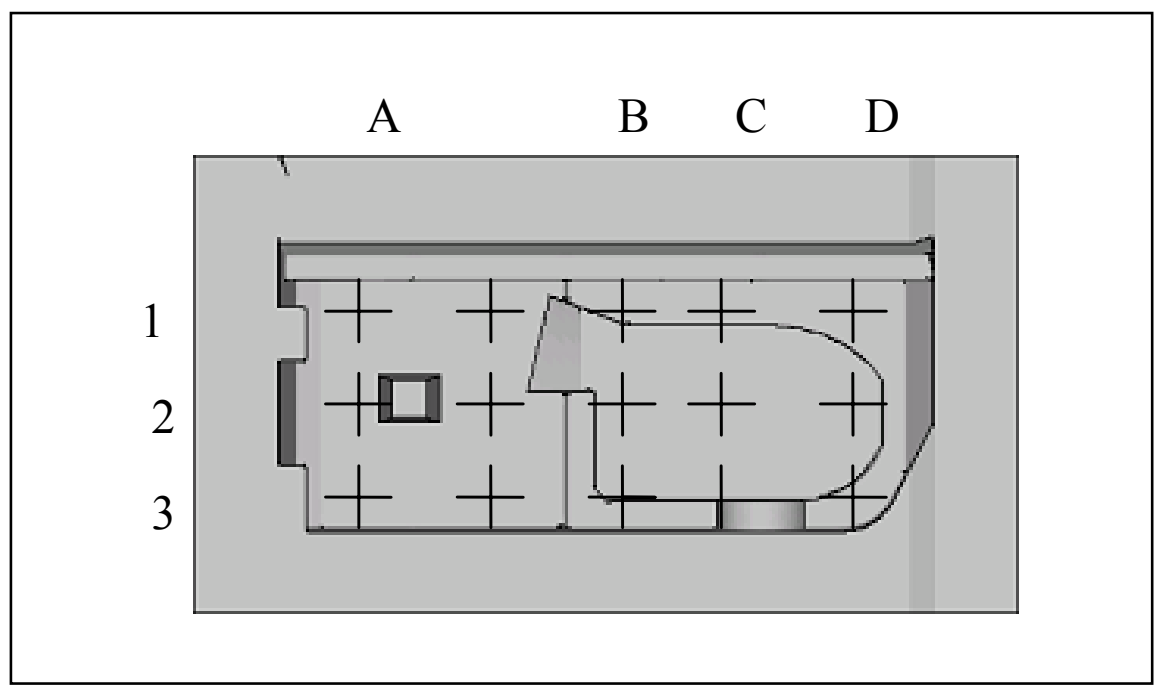

Fig. 5. Locations on mould surface for temperature recording. 


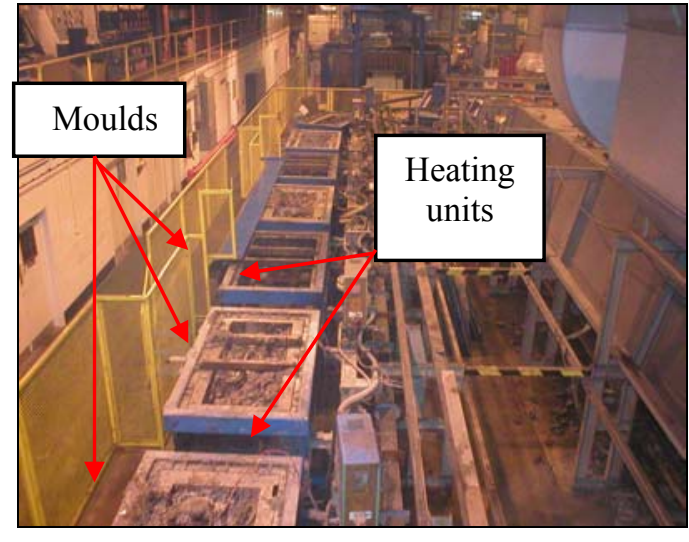

Fig. 6a. Carousel C21 with 20 mould carriages.

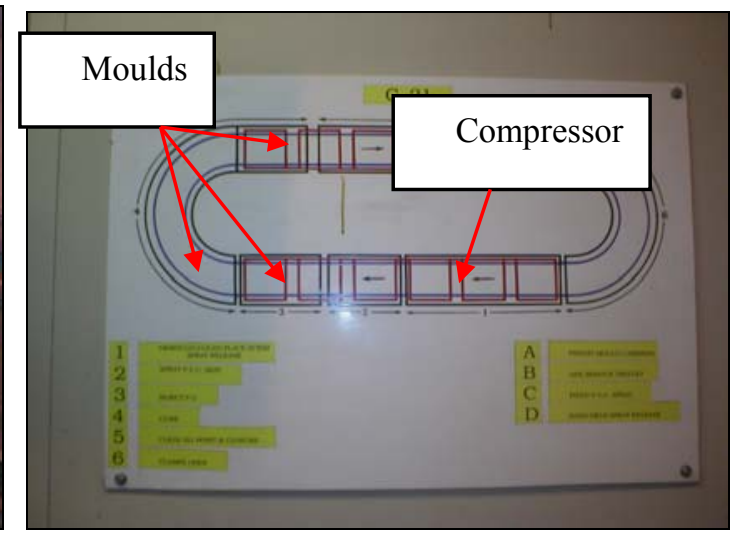

Fig. 6b. Layout of Carousel C21.

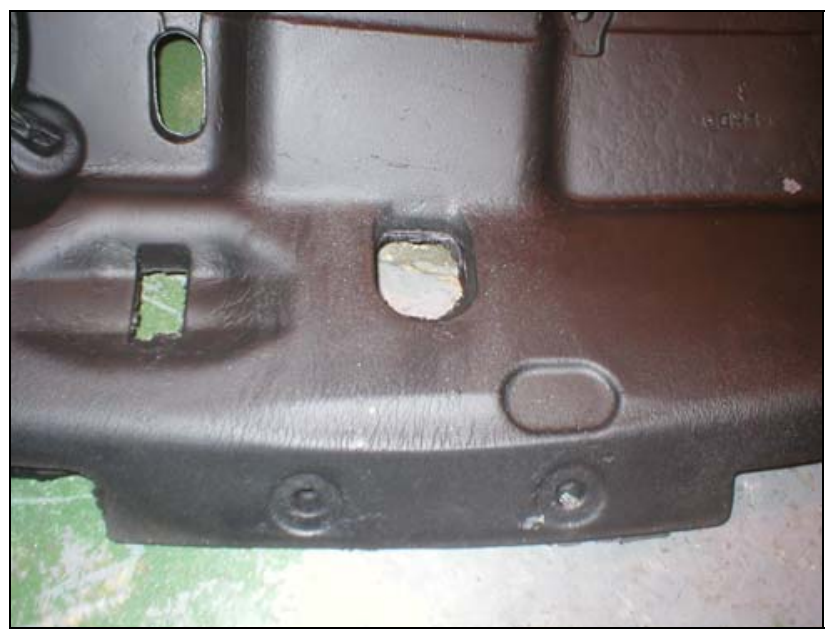

Fig. 7. Mid-section of dash-cover for Land-Rover Freelander.

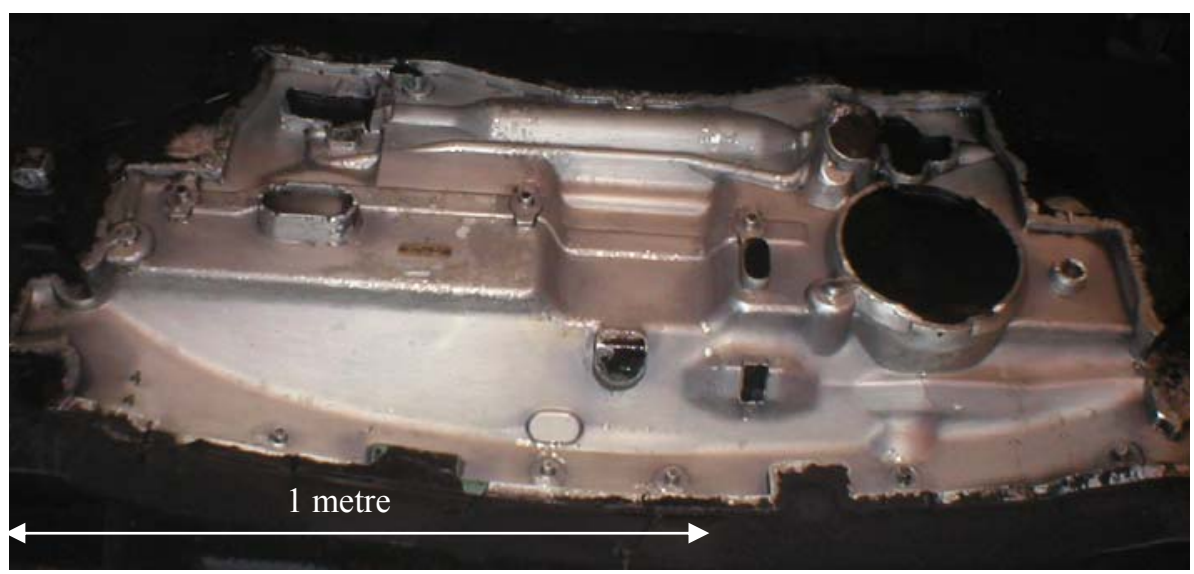

Fig. 8. Tool 2. 